\title{
Aportes internacionales de las experiencias de justicia transicional para Colombia*
}

\author{
https://doi.org/10.22395/ojum.v17n35a13 \\ Dimaro Alexis Agudelo Mejía" \\ Liliana Damaris Pabón Giraldo*** \\ Luis Orlando Toro Garzón **** \\ Mónica María Bustamante Rúa ${ }^{* * * *}$ \\ Orión vargas Vélez ${ }^{* * * * *}$
}

Recibido: 01 de octubre del 2018 • Aprobado: 03 de diciembre del 2018

\section{RESUMEN}

El presente trabajo aborda las experiencias de justicia transicional en América del Sur, América Central, Europa, África y Asia a fin de extraer aportes que sean aplicables a la justicia transicional en Colombia. Para ello, mediante una metodología exploratoria, descriptiva y analítica, se hace un acercamiento al concepto de justicia transicional y se describen las experiencias de cada una de estas regiones para resaltar que muchas de ellas se han preocupado por establecer medidas no judiciales en las que prima la verdad sobre la justicia, también hay otros casos en los que se han centrado en establecer medidas judiciales en las cuales prima la justicia y el resarcimiento a la víctima. Una vez analizadas estas experiencias se da respuesta a la pregunta de investigación: ¿Cuáles son los aportes de las experiencias de justicia transicional de otras regiones a la justicia transicional en Colombia? Se concluye que Colombia debería respetar los estándares internacionales, los derechos humanos y garantizar el reconocimiento de los derechos a las víctimas para lograr una paz estable y duradera.

Palabras clave: conflicto; paz; justicia transicional; víctima.

* Este artículo es el resultado del proyecto de investigación denominado "Perspectivas y desafíos de la justicia transicional en Colombia", llevado a cabo por los autores del mismo en calidad de investigadores y financiado por la Universidad de Medellín.

* Abogado, magíster en Derecho Procesal y Doctor en Derecho Procesal Contemporáneo de la Universidad de Medellín, Colombia. Profesor de tiempo completo de la misma universidad. Correo electrónico: dagudelo@udem.edu.co

*** Abogada, magíster en Derecho Procesal de la Universidad de Medellín, magíster en Derecho Procesal y Doctora en Derecho de la Universidad Nacional de Rosario, Argentina. Profesora de tiempo completo de la Universidad de Medellín. Correo electrónico: ldpabon@udem.edu.co

...* Abogado, magíster en Derecho Procesal, candidato a Doctor en Derecho Procesal Contemporáneo de la Universidad de Medellín. Profesor de tiempo completo de la misma universidad. Correo electrónico: ltoro@udem.edu.co

***** Abogada, magíster en Derecho Procesal de la Universidad de Medellín, magíster en Derecho Procesal y Doctora en Derecho de la Universidad Nacional de Rosario, Argentina. Profesora de tiempo completo de la Universidad de Medellín. Correo electrónico: mmbustamante@udem.edu.co

....** Abogado, magíster en Derecho Procesal de la Universidad de Medellín, Doctor en Filosofía de la Universidad Pontificia Bolivariana. Profesor de tiempo completo de la Universidad de Medellín. Correo electrónico: ovargas@udem.edu.co 


\title{
International Contributions of Transitional Justice Experiences for Colombia
}

\begin{abstract}
This paper addresses transitional justice experiences in South America, Central America, Europe, Africa and Asia to identify applicable contributions to transitional justice in Colombia. With an exploratory, descriptive and analytical methodology, the paper approaches the concept of transitional justice and the experiences of each of aforementioned regions to highlight that many of them have been concerned with establishing non-judicial measures in which truth is put above justice. Other cases in have focused on establishing judicial measures in which justice and victim compensation prevail. After analyzing these experiences, the research question "What are the transitional justice experiences' contributions of other regions to transitional justice in Colombia?", is answered. The paper concludes that Colombia should respect international standards and human rights and guarantee the recognition of the rights of victims to achieve a stable and lasting peace.
\end{abstract}

Keywords: conflict; peace; transitional justice; victim.

\section{Colaborações infernacionais das experiências de justiça transicional para a Colômbia}

\section{RESUMO}

O presente trabalho aborda as experiências de justiça transicional na América do Sul, na América Central, na Europa, na África e na Ásia a fim de extrair colaborações que sejam aplicáveis à justiça transicional na Colômbia. Para isso, por meio de uma metodologia exploratória, descritiva e analítica, faz-se uma aproximação ao conceito de justiça transicional e descrevem-se as experiências de cada uma dessas regiões para ressaltar que muitas delas se preocuparam em estabelecer medidas não judiciais nas quais a verdade prima sobre a justiça e também há outros casos nos quais se centrou em estabelecer medidas judiciais nas quais se prima pela justiça e pelo ressarcimento à vítima. Após a análise dessas experiências, dá-se resposta à pergunta da pesquisa: Quais são as colaborações das experiências de justiça transicional de outras regiões para a justiça transicional na Colômbia? Conclui-se que a Colômbia deveria respeitar os padrões internacionais e os direitos humanos, além de garantir o reconhecimento dos direitos das vítimas para alcançar uma paz estável e duradoura.

Palavras-chave: conflito; paz; justiça transicional; vítima. 


\section{INTRODUCCIÓN}

La justicia transicional es un tema y compromiso de actualidad en Colombia que ha adquirido especial relevancia a partir de la firma del acuerdo de paz entre el Gobierno Nacional y la guerrilla de las FARC-EP -denominado el Acuerdo del Teatro Colón-, firmado en Bogotá el 24 de noviembre del 2016, por medio del cual se pactó la terminación del conflicto armado y la construcción de una paz estable y duradera. Para el cumplimiento de lo acordado, es importante conocer e integrar las experiencias de justicia transicional de otras regiones a fin de comprender el presente en Colombia de cara a las experiencias del pasado.

Para tal efecto, este artículo tiene por objeto el estudio comparado de las experiencias de justicia transicional en regiones tales como: América del Sur, América Central, Europa, África y Asia, por considerar que estas regiones que han sido en el pasado escenarios de conflicto o han estado regidos por sistemas políticos dictatoriales que han comprometido la dignidad humana, el desarrollo social y la institucionalidad como esencia de los Estados, poseen experiencias aplicables en el caso de la justicia de transición en Colombia. Para ello se formuló la siguiente pregunta de investigación: ¿Cuáles son los aportes de las experiencias de justicia transicional de otras regiones para la justicia transicional en Colombia?

Se empleó una metodología exploratoria, descriptiva y analítica. Los datos que aquí se describen en relación con la justicia transicional se obtuvieron de fuentes doctrinales de orden nacional e internacional e informes presentados por organizaciones internacionales inspiradas en la paz en los países con conflictos o con regímenes dictatoriales. Para su desarrollo, se parte del concepto de justicia transicional y la descripción y análisis de las experiencias de justicia transicional en las regiones objeto de estudio, para luego identificar los aportes que estas experiencias presentan a la justicia transicional en Colombia.

\section{CONCEPTO DE JUSTICIA TRANSICIONAL}

La justicia transicional se entiende como "la aplicación de una variedad de mecanismos aplicados a crímenes en masa y violaciones de derechos humanos acaecidos en un contexto de conflicto o de represión polí tica" (Seils, 2009, p. 22). Implica, según este autor, proporcionar a las víctimas afectadas por estos crímenes un cierto nivel de justicia, pero principalmente, se busca la restauración de la "confianza" (Seils, 2009, p. 21).

Por su parte, para la Corte Constitucional colombiana la justicia de transición supone una búsqueda en pos de solucionar fuertes tensiones entre la justicia y la paz, a fin de satisfacer los derechos de las víctimas y lograr el cese de hostilidades, de tal manera que se evite el retorno de la violencia y se consoliden reformas que afiancen verdaderamente la paz (Corte Constitucional, sentencia C-579 de 2014). Para lograr tal objetivo, 
Dimaro A. Agudelo M., Liliana D. Pabón G., Luis O. Toro G., Mónica M. Bustamante R. y Orión Vargas V.

el máximo tribunal indicó que "se requerían desarrollar objetivos especiales tales como: el reconocimiento de las víctimas, el restablecimiento de la confianza pública, la reconciliación y el fortalecimiento de la democracia" (Pabón, Bustamante y Toro, 2017, p. 154).

Al respecto, el profesor Kai Ambos de Alemania, planteó que dicho concepto se ocupa de la justicia en sociedades en transición y supone un conjunto de medidas de naturaleza judicial o no judicial, cuyo éxito dependerá del grado en que la misma contribuya a la reconciliación. En ese sentido, reflexiona que la justicia de transición "comprende el entero ámbito de los procesos y mecanismos asociados con los intentos de una sociedad para afrontar un legado de abusos a gran escala del pasado, para asegurar responsabilidad, rendir justicia y lograr reconciliación" (Ambos, 2009, p. 23).

En este trabajo se asume la justicia transicional como un conjunto de mecanismos judiciales y no judiciales que diseña e implementa un Estado para la superación de graves violaciones a los derechos humanos que se presentan en el marco de un conflicto armado o de un régimen dictatorial. Para ello se parte de los elementos de la transición, los cuales son "la temporalidad para la construcción de la paz, la excepcionalidad, la territorialidad y la participación" (Bustamante, Pabón y Toro, 2017. pp. 111-115).

\section{EXPERIENCIAS DE JUSTICIA TRANSICIONAL EN OTRAS REGIONES}

\subsection{En América del Sur}

El Centro Internacional de Justicia Transicional indicó que América Latina es uno de los continentes pioneros en enfoques de justicia transicional. Muestra de ello es lo que ha acontecido en países como Argentina, Chile, Brasil, Uruguay y Perú, entre otros, tal como se muestra a continuación:

En 1983 Argentina puso fin a siete años de terrorismo producto de la dictadura militar. Para ello, creó la Comisión Nacional sobre Desaparición de Personas (Conadep) (Decreto Nro. 187/83), la primera comisión oficial -incluso a nivel mundial- en este sentido, la cual, con su informe "Nunca más", ha servido como parámetro para otros procesos de justicia transicional en el mundo. En este país se han adelantado procesos de responsabilidad penal y se han decretado indultos. Para el 2000, el gobierno argentino anuló leyes de impunidad y por esta razón, se asevera que han avanzado en establecer la responsabilidad de algunas personas involucradas en la dictadura. También, existe un programa de reparaciones administrativas y centros de la memoria.

Al respecto, Ricardo Gil Lavedra indica que en Argentina la persecución criminal no ha sido continua y la divide en dos etapas: una en la cual se recuperó la democracia a finales de 1983 y se indultó a militares condenados durante ese 
período; y otra que refiere a un fallo del 2005 en el cual se declaró la nulidad de las leyes de "punto final" (Ley 23.492) y "obediencia debida" (Ley 23.521) que dejaban a autores de hechos atroces sin castigo. Con ello, tuvo lugar una reapertura de algunos casos judiciales, nuevas denuncias, condenas y morosidad en el proceso (Gil, 2009, p. 43).

El proceso en Argentina partió de una investigación de los crímenes de la dictadura, previsto en el código penal común, con un procedimiento militar breve, un juicio sumario con audiencia oral y pública y un rasgo acusatorio (Gil, 2009, p. 48). En esa época el desarrollo de reglas y precedentes internacionales era escaso, no se empleaban los términos "delitos de lesa humanidad" y "ius cogens", las convenciones de derechos humanos tampoco estaban vigentes. En Argentina en un principio, se preocuparon más por la verdad que por la justicia, se presentaron avances en la aclaración de los hechos, pero sin vinculación a una sanción penal.

Por su parte, Parenti y Pellegrini (2009) afirman que Argentina, en lo que concierne a la reacción penal, pasó por diversas etapas: una etapa de persecución penal limitada en la cual se investigaron y juzgaron únicamente los autores y partícipes que estuvieron más comprometidos con la represión. La segunda etapa fue de impunidad, su eje fue limitar e impedir juicios penales y el cumplimiento de sentencias. La tercera etapa se denominó "la erosión de la impunidad", en ella se deslegitimaron las políticas con relación a la impunidad, se presentaron reclamos de víctimas, familiares y derechos humanos y se buscó encaminar el abordaje hacia el estándar del derecho internacional y el respeto a los derechos humanos, de esta forma iniciaron los juicios en pos de la verdad. Se finalizó con la etapa de superación de la impunidad, en la cual se hicieron posibles los procesos que en la actualidad están están en trámite (2009).

Conforme con lo expuesto, en Argentina se han implementado medidas no jurisdiccionales que buscan la reparación, restitución y dilución del pasado conflictivo, tales como: la cinematografía y libertad de expresión, la ley de nacionalidad, ley de indemnización a ex presos políticos -que otorgó beneficios económicos a personas durante el estado de sitio-, ley de beneficio económico a personas ausentes por desaparición forzada y a personas fallecidas en manos de las fuerzas armadas - ley que consagró la posibilidad de declarar judicialmente la ausencia por desaparición forzada de una persona, localización y restitución de la identidad de niños sustraídos en el marco de la represión ilegal-, archivos y espacios para la memoria, medidas legislativas para la preparación de los juicios y para afianzar valores menospreciados durtante la dictadura (Parenti y Pellegrini, 2009).

En el caso de Bolivia, Elizabeth Santalla Varga, indica que del 4 de noviembre de 1964 al 10 de octubre de 1982 se dio una ola de violencia política generada por agentes de gobierno inconstitucionales. 
Dimaro A. Agudelo M., Liliana D. Pabón G., Luis O. Toro G., Mónica M. Bustamante R. y Orión Vargas V.

A partir de esta fecha se reinstauró la democracia. Para contrarrestar esta época, se creó la comisión de verdad para la desaparición forzada de personas, luego se llevó a cabo el resarcimiento a las víctimas por violaciones de derechos humanos y se emitió sentencia condenatoria contra el ex dictador Luis García Meza, lo que dio lugar, en otro extremo, a una alta impunidad durante este período, por falta de investigación y por la exclusión del proceso penal a algunos responsables de violaciones de derechos humanos. Bolivia reaccionó a la justicia transicional con mecanismos penales y no penales (2009).

En Brasil, el gobierno militar terminó en 1985. Los avances en materia de responsabilidad penal en la justicia transicional no han sido los esperados, no obstante, se discute sobre la posibilidad de mantener la ley de amnistía y en los últimos gobiernos se han creado programas de reparación a las víctimas. Frente al tema, María Thereza Rocha de Assis Moura, Marcos Alexandre Coelho Zilli y Fabiola Girão Monteconrado Ghidalevich, en un informe nacional al respecto, indicaron que la época de transición ha sido lenta y gradual. Durante este periodo se promulgó una ley de amnistía en 1979, lo que explica la ausencia de medidas de carácter penal, ya que se hizo énfasis en medidas no penales, las cuales tardaron en implementarse -solo hasta 1995- con la creación de una comisión especial para examinar casos de desaparecidos políticos y se instaló la comisión de amnistía. Debido a las comisiones creadas, se dice que en Brasil predominaron los mecanismos alterna- tivos de superación del pasado, lo que llevó a una demora excesiva del Estado brasilero en la adopción de leyes para que las víctimas y familiares buscaran formas de reconocimiento a las violaciones de sus derechos fundamentales (Rocha, Coelho y Monteconrado, 2009).

Por su parte, la dictadura de Augusto Pinochet en Chile terminó en 1990 y esperaron nueve años para dar inicio a los primeros juicios por crímenes cometidos durante esta. Se han creado dos comisiones de la verdad con mandatos diferentes, una en 1991 y otra en el 2005, estas han comprobado la comisión de algunos crímenes, tales como tortura, desaparición forzada y prisión política del régimen. Algunos de los responsables ya cumplen condenas en cárceles del país y se creó -al igual que en Argentina, pero con otra denominación - el Programa de Reparación y Atención Integral en Salud y Derechos (Prais), a fin de ayudar con las secuelas de la violencia y el abuso.

Frente al tema, Roberto Garretón (2009) indica que en Chile la dictadura se instauró de forma paulatina con la adopción de medidas legislativas, así: traspaso de competencias de la justicia ordinaria a la justicia militar; sustitución de la justicia militar en tiempos de paz por una en tiempos de guerra, con indefensión para los procesados; aumento de penas para delitos políticos, incluso pena de muerte; recurso permanente a los estados de excepción para detener y/o expulsar del país a disidentes sin juicio alguno; legitimación de las incomunicaciones y la impunidad a 
los violadores de derechos humanos, por decreto de amnistía desde 1978.

Como consecuencia, en Chile la transición también contó con varias etapas: inicialmente se restauró la democracia, pero se mantuvo la impunidad hasta 1998. Posterior a ello, cuando se detuvo a Pinochet en Londres, acusado de crímenes de lesa humanidad, genocidio, torturas y terrorismo, se descubrió que no se había implementado ninguna justicia en este país y se comenzó con el reconocimiento de atrocidades, investigaciones y procesos abiertos, para lo que se tuvo en cuenta la defensa de los derechos humanos y el derecho internacional de los derechos humanos. Se buscó entonces el derecho a la justicia, la verdad y la reparación en calidad de víctima.

Al respecto, José Luis Guzmán Dalbora (2009), en su informe sobre Chile, indicó que la justicia de transición en este país ha implementado mecanismos de verdad a través de las comisiones de la verdad y reparación, la primera en 1990 con la Corporación Nacional de Reparación y Reconciliación. Para continuar su misión, se crearon luego la Comisión Nacional de Verdad y Reconciliación, y la Comisión Nacional sobre Prisión Política y Tortura -también llamada Comisión Valech-, la cual tenía por objetivo atender los casos de las personas que sufrieron privación de la libertad y tortura por razones políticas a manos de agentes del Estado. Ambas comisiones buscaban la reparación, reconciliación y prevención, paralelamente se instauraron juicios penales.
Las propuestas de reparación individual tuvieron eco hasta el 2004, cuando mediante la Ley 19992 del 24 de diciembre, se estableció la pensión vitalicia para las víctimas nombradas como prisioneros políticos y torturados, y un bono único para menores que nacieron durante la prisión de sus progenitores o fueron detenidos. Es decir, se recibe por parte del Estado un apoyo económico y técnico, la rehabilitación de lesiones físicas y además, la garantía de poder continuar sus estudios escolares y superiores de forma gratuita (2009).

Paraguay, bajo el régimen de Stroessner (1954 - 1989), vivió una dictadura y la concentración del poder en manos del ejecutivo; para cerrar esta etapa no se implementaron mecanismos para sacrificar la verdad y reconciliación por encima de la justicia. Allí, se establecieron recursos legales para que las víctimas obtuvieran una reparación económica y simbólica en 1996, en el 2003 se creó una comisión de verdad y justicia (Alfonso, 2009, pp. 345-354). Por tanto, Paraguay acudió a la aplicación clásica del derecho penal, a judicializar a los presuntamente responsables por violaciones de derechos humanos, a la creación de una comisión de verdad y justicia y la instauración de recursos a favor de las víctimas. Mecanismos que no cumplieron su finalidad, por el alto índice de impunidad y la duración prolongada de los procesos.

En Perú, el proceso de posconflicto se genera con la renuncia y posterior fuga del expresidente Alberto Fujimori, quien 
Dimaro A. Agudelo M., Liliana D. Pabón G., Luis O. Toro G., Mónica M. Bustamante R. y Orión Vargas V.

atenuó el conflicto armado generado por Sendero Luminoso, al cual respondieron con fuerza agentes del Estado. Allí se creó, al igual que en los países anteriores, una comisión de la verdad y la reconciliación (CVR) que funcionó entre 2001 y 2003. Está pudo establecer el número de personas muertas y desaparecidas en manos de los grupos al margen de la ley y de las fuerzas armadas y policiales. La CVR tuvo una característica única: el equipo de judicialización, el cual "debía investigar crímenes específicos para después transmitir la información al Ministerio público" (Seils, 2009, p. 34).

Al respecto, el Centro Internacional de Justicia Transicional (ICTJ) indica que este es un proceso difícil, sin embargo, ha tenido avances en términos de responsabilidad penal y violaciones de derechos humanos, como por ejemplo la condena al expresidente Fujimori por participar en crímenes de lesa humanidad (International Center For Transitional Justice [ICTJ], 2009); al igual que otros países, contó con un programa de reparaciones colectivas y un museo de la memoria.

Así las cosas, los mecanismos empleados fueron la comisión de la verdad y la reconciliación (creada en 2001) a fin de esclarecer las violaciones a los derechos humanos que tuvieron lugar durante el conflicto interno y promover la reconciliación. La comisión formuló recomendaciones para superar esas brechas con reparaciones a los afectados por el conflicto interno, hicieron mención a reparaciones simbólicas, reparaciones en salud y educación, restitución del estatus pleno de ciudadanía y remoción de estigmas legales, reparaciones económicas y preparación de reformas institucionales y experiencia de reconciliación. Esto demuestra que en Perú se adoptaron medidas de restitución, reparación/compensación, rehabilitación y no repetición; para ello se crearon programas como el Plan Integral de Reparaciones, se creó el registro único de víctimas a fin de registrar e inscribir a todas las víctimas para hacer viable la reparación integral y se estableció un consejo de reparaciones, cuya función fue individualizar, calificar y acreditar la condición de víctima (Caro, 2009).

En Uruguay, el gobierno militar finalizó en 1985 pero no ha habido avances en justicia transicional, materia penal, ni en el esclarecimiento histórico, aunque subsiste la esperanza de que la situación cambie. En este país se creó la Ley de caducidad de la pretensión punitiva del Estado en 1986, la cual hacía referencia a una amnistía virtual para los criminales y fue sometida a la opinión pública a través de un plebiscito nacional. Al respecto, Pablo Galain Palermo indica que se restauró el Estado de derecho y como producto, el parlamento dictó una ley sobre amnistía en 1985, con respecto a todos los delitos políticos, comunes y militares conexos cometidos a partir del 1 de enero de 1962. Como consecuencia, múltiples manifestaciones de descontento y repudio por parte de las víctimas han tenido lugar. Para devolver la paz a los uruguayos, en el 2000 se creó la comisión de paz, en aras de la 
verdad y la reconciliación entre las partes enfrentadas (Galain, 2009).

En Uruguay no se recurrió a forma alguna de derecho penal diferencial o premial para alcanzar la paz, y solo hasta el 2006 se instauró una pensión especial reparatoria para algunas personas detenidas y procesadas con privación de la libertad por la justicia militar en la época de la dictadura; también se generó una restitución simbólica de la dignidad ultrajada por el aparato estatal (Galain, 2009).

Por su parte, Colombia hace parte del grupo de países que busca implementar mecanismos de justicia transicional, tema frente al cual se comenzó a trabajar desde el 2005 con la ley de víctimas en el proceso de desmovilización de grupos paramilitares, y posteriormente con la firma del Acuerdo del Teatro Colón entre el gobierno y las Fuerzas Armadas Revolucionarias de Colombia (FARC-EP) en el 2016, cuya finalidad era buscar la verdad, la justicia y la reparación conforme a estándares internacionales. No obstante, este es un tema que demanda vital atención para lograr una implementación real del proceso de paz y alcanzar una paz estable y duradera que haga frente a las consecuencias políticas, jurídicas, económicas e incluso culturales fruto de la transición en la cual nos encontramos inmersos.

Lo expuesto sobre los casos de América del Sur demuestra que cada experiencia de justicia transicional es diferente de las demás, aunque puedan guardar ciertas coincidencias, esto se debe a diversos factores, tales como:

$$
\begin{aligned}
& \text { La magnitud y la naturaleza } \\
& \text { del conflicto, la conformación } \\
& \text { social y cultural de la sociedad } \\
& \text { y especialmente la relación de } \\
& \text { fuerzas entre facciones po- } \\
& \text { líticas, sociales y/o militares } \\
& \text { antagonistas existente en un } \\
& \text { momento dado, condicionan } \\
& \text { la elección de los mecanismos } \\
& \text { concretos de un proceso de } \\
& \text { transición. De estos factores } \\
& \text { dependerá qué medidas podrá } \\
& \text { poner en práctica un Estado, } \\
& \text { qué características concretas } \\
& \text { podrán tener tales medidas y en } \\
& \text { qué momento podrán ser adop- } \\
& \text { tadas. (Malarino, 2009, p. 416) }
\end{aligned}
$$

No obstante, se observa que los procesos de justicia transicional se han preocupado por una justicia reconstitutiva, entendida por Paul Seils como "la reconstitución de lazos de confianza entre los ciudadanos y las instituciones" (2009, p. 22). Es así que la reconciliación se erige como uno de los mecanismos deseados en los ejemplos de justicia transicional en el mundo en pos de alcanzar la democracia estatal.

\subsection{En Centroamérica}

A finales del siglo XIX y durante gran parte del siglo XX, la región centroamericana fue un referente internacional debido a los conflictos internos que atravesó por fenómenos económicos, sociales y políticos, así como por los intentos de llegar al poder por la vía de la confrontación armada. Como consecuencia, los escenarios de conflicto centroamericano 
Dimaro A. Agudelo M., Liliana D. Pabón G., Luis O. Toro G., Mónica M. Bustamante R. y Orión Vargas V.

se presentaron con las siguientes connotaciones políticas y sociales:

En Guatemala el conflicto armado se escaló por fenómenos políticos y sociales, e incidentes tales como la expropiación de tierras a la iglesia y a los indígenas, y la idea de mercados abiertos en pos de incentivar la producción y exportación de café; como consecuencia se generó la deslegitimación ante la falta de protección al derecho a la propiedad sobre las tierras, igualmente por el paso de un gobierno autoritaritario en 1944, a la idea de gobierno socialista y espiritual que buscaba devolver las tierras a los indígenas y acabar con las barbaries anteriores. Las ideas socialistas fueron interpretadas como brotes de comunismo por otros Estados, lo que germinó en el nacimiento de movimientos revolucionarios y confrontaciones armadas por el poder y los monopolios económicos.

La literatura del conflicto data de cuando Yo Sosa lanzó el primer movimiento guerrillero, luchando desde la selva, fue derrotado con apoyo internacional, y surgió un reagrupamiento guerrillero en 1963 con el nombre de Fuerza Armada Revolucionaria (FAR) con doctrina marxista y con el giro cubano de Fidel. Se cree que unas 8.000 personas perdieron la vida en los enfrentamientos. En los documentos históricos se afirma que este país en las décadas de 1970 y 1980 estuvo convulsionado por confrontación de ideales, posiciones sociales, políticas y religiosas adversas, influenciadas por intereses estatales foráneos.
En cuanto al proceso de paz y justicia transicional, se evidencia que en 1990 se dieron los primeros acercamientos de paz, ante el debilitamiento guerrillero y la democratización del gobierno, se aprecia escrituralmente que este resultado también fue consecuencia de la terminación de la guerra fría entre la Unión Soviética y los EE. UU.

El mayor logro -como fenómeno social- para Guatemala es la paz, se predica que llegó en 1996, posterior al resto de la región, y con la URNG (Unidad Revolucionaria Nacional Guatemalteca) tomando parte en las posteriores elecciones como partido político. Se afirma que en la confrontación armada 200.000 personas perdieron la vida, unos 50.000 se dieron por desaparecidos y unas 600 comunidades fueron destruidas en 36 años de conflicto (Díaz, Romero y Moran, 2010; Aguirre, 2014).

En El Salvador el conflicto inició en 1932 con escenarios de desestabilidad económica, política y social, debido a la caída del cultivo del café como único factor de producción y sostenimiento, la crisis mundial, el surgimiento de movimientos de tipo comunista, la toma del poder por parte de los militares y posteriormente la transición al comunismo al mando de Farabundo Martí y a las expresiones de subversión cuando no se le permitió inscribir su candidatura para elecciones presidenciales, lo cual generó la denominada "matanza" con 20.000 víctimas, en un rango de dos meses. A razón de ello, 
se seccionó a los comunistas entrados en armas.

En 1972 nuevamente se presentaron episodios de violencia con el surgimiento del Ejército Revolucionario Popular (ERP), integrado por excomunistas y cristianodemócratas, de este surgieron las Fuerzas Armadas de Resistencia Nacional. En 1975 apareció el Partido Revolucionario de los Trabajadores Centroamericanos (PRTC) con participación de disidencias del comunismo de Farabundo Martí.

Entre 1979 y 1980 -el escenario más crudo del conflicto-, inició una confrontación que duró diez años, con un saldo de 75.000 víctimas y que enfrentó a un ejército fortalecido por necesidad, que pasó de 10.000 a 50.000 hombres, sumándose a sus esfuerzos otros organismos de seguridad y organizaciones de justicia privada que sumaban aproximadamente 10.000 hombres, las cuales se enfrentaron a movimientos revolucionarios pertenecientes al Frente Farabundo Martí de Liberación Nacional (FMLN), de los cuales se afirma que tenían entre 5.000 y 10.000 hombres.

Posterior a ello, se dieron otros episodios de unificación subversiva, y una clara hegemonía de poder rural de las guerrillas y de delimitación del control estatal en las partes urbanas. Luego de varios intentos con apoyo nicaragüense y cubano (1981) de tomarse el poder, a través de los planes de toma final de San Salvador, el ejército salvadoreño fortalecido por apoyo internacional logró el debilitamiento de las guerrillas, situación por la cual bajo la presidencia de Duarte se dio lugar a la firma de los acuerdos de paz en 1991 (Díaz, Romero y Moran, 2010; Martínez Ventura, 2009).

Desde inicios del siglo XIX hasta el siglo XX en Nicaragua se presentó un conflicto interno ligado a componentes de tipo expansionista de países tales como EE. UU., Inglaterra, Rusia y Cuba. En el marco de este conflicto, se presentaron acciones continuas de hostilidad en varios de los territorios que componen el Estado, continuas acciones de hostilidad extranjera dieron lugar a pugnas políticas internas entre conservadores y liberales, que, según los estudios de situación histórica, llevaron incluso a una corta guerra civil.

Durante los gobiernos de José Santos Zelaya -destituido en 1909-, Anastasio Somoza (1933 - 1956), y la dinastía Somoza (1933-1979) se presentaron conflictos de orden subversivo por descontento con los gobiernos enunciados y luego de múltiples golpes, en 1979 colapsó este último gobierno y triunfó la revolución con los hermanos Ortega al frente. A partir de entonces, los contactos del gobierno fueron Cuba, la Unión Soviética y Bulgaria. Daniel Ortega se puso al frente, implementó un ejército nacional y recibió apoyo armado para enfrentar a los EE. UU. en eventuales ataques.

Posterior a ello, se siguieron presentando enfrentamientos entre el gobierno sandinista y los grupos antisandinistas hasta 1988 cuando - sin que pueda decirse quienes fueron vencedores o vencidos- 
Dimaro A. Agudelo M., Liliana D. Pabón G., Luis O. Toro G., Mónica M. Bustamante R. y Orión Vargas V.

después de 25.000 muertos y 700.000 desplazados, se firmaron los acuerdos de Sapoa' en 1988.

En la historia de Nicaragua se denotan cambios de gobiernos de facto, a gobiernos democráticos y cambios de gobiernos con ideas comunistas a gobiernos con ideas socialistas, de conflictos por vía armada a negociaciones de terminación acordada, lo que es significativo para la cultura global compartida de justicia transicional (Díaz, Romero y Moran, 2010; Chernick, 1998).

En el siglo XIX en Honduras se presentó la misma situación que vivían todos los demás países centroamericanos, en cuanto a las disputas políticas y sociales desde ideales conservadores y liberales, respecto a grupos subversivos y escenarios de decisiones enmarcados en lineamientos de justicia transicional.

Este país no se precisa como fortín de la revolución guerrillera, no obstante, en el siglo XIX algunos grupos revolucionarios intentaron tener asiento en esta geografía, tales como el Movimiento Popular de Liberación Cinchones (1982), las Fuerzas Revolucionarias Populares Lorenzo Zelaya (FPR) y el Partido Revolucionario de los Trabajadores Centroamericanos-Capítulo

\footnotetext{
Hace referencia a la denominación que se dio a los acuerdos de paz firmados en 1988 en Centroamérica entre el gobierno de Nicaragua y la denominada contra nicaragüense para terminar las acciones armadas y con ello el derramamiento de sangre; tales acuerdos se firman después de muchos fracasos y de intento de armonización de la paz en Centroamérica a través del denominado Grupo de Contadora, por falta de consenso en cuanto a las ideas políticas y sociales y por la presencia viva de injerencias internacionales.
}

de Honduras (PRTC-H); sin embargo, con el apoyo militar de los EE.UU., esas expresiones revolucionarias fueron confinadas (Díaz, Romero y Moran, 2010, pp. 31-34).

Históricamente, Costa Rica y Panamá no tuvieron incidencia en el conflicto centroamericano en cuanto a luchas subversivas, si bien es cierto que presentaron escenarios de disputas políticas internas, tales disputas no pasaron al nivel de conflicto armado desde las caracterizaciones del protocolo II de Ginebra.

En el caso de Costa Rica, según documentos históricos, solamente en 1948 se dio una guerra civil de seis semanas entre los comunistas y el gobierno no constituido de Figueres ${ }^{2}$, en este contexto y luego de la terminación de la guerra, Figueres abolió al ejército nacional. Igualmente, en 1979 el triunfo del Frente Sandinista en Nicaragua trajo a Costa Rica la presencia de contras, se relata igualmente que el mismo Edén Pastora, con su Alianza Democrática Revolucionaria (ARDE) se asentó durante 1982 y 1983 en el país, que pequeñas guerrillas y grupos paramilitares aparecieron, pero el gobierno del momento reaccionó con rapidez y declaró "la neutralidad perpetua, activa y desarmada" (Díaz, Romero y Moran, 2010).

Los acuerdos de paz en esta región estuvieron precedidos por tres generaciones de diálogo, ello es, los realizados antes y hasta las denominadas Esquipulas de 1986; los de segunda generación, es decir las

José María Figueres Olsen, presidente de la República de Costa Rica entre 1994 y 1998. 
denominadas Esquipulas II de 1987; y los de tercera generación como derivación de Esquipulas I y II, además de los acuerdos complementarios a nivel interno de cada país que contribuyeron a las transiciones hacia gobiernos democráticos, desmilitarizaciones y desmovilizaciones, a pesar de las complejidades de negociación de cada país (Matul y Ramírez, 2009). Es indudable que este ámbito de transición del conflicto a la paz se dio bajo los compromisos de giros en la política económica, reformas al sistema político, fortalecimiento de los derechos y garantías, orientación de la democracia hacia la representación efectiva, reformas constitucionales para el mejoramiento de lo social y la correcta división de poderes y desmilitarización del Estado de Costa Rica.

El ámbito de justicia transicional que se adoptó en la región fue consecuente con la doctrina generalizada de orden nacional e internacional en cuanto a que estuvo edificada sobre el objetivo de garantía de cambios políticos sustanciales, en el paso de regímenes opresores a sistemas democráticos, el tratamiento especial en el ámbito de la responsabilidad penal, la reparación de las víctimas, el fortalecimiento económico y el desarrollo social sostenible (Rodríguez, 2011).

Desde una postura analítica de la justicia transicional, y la obra de Jon Elster (2006) se resalta que los componentes esenciales para lograr los cometidos de la justicia transicional son: el análisis de los autores de los delitos y su forma de identificación, clasificación y procesamiento penal; el estudio de las víctimas y los daños materiales y morales a partir de la recuperación de la memoria de lo sucedido; la identificación de todas las víctimas y las formas y garantías de efectivización de justicia desde la compensación, que obviamente debe ser integral.

Rodríguez (2011) señala que Centroamérica, tras poner fin a los conflictos armados, enfrentó los retos inherentes a la consolidación de la democracia, la gobernabilidad y la paz, que con los procesos de transición se crearon en Guatemala y El Salvador comisiones de la verdad no judiciales, así como iniciativas de memoria desde el Estado y la sociedad civil. También operaron varios programas oficiales para la reparación a las víctimas y se inauguraron un par de museos de la memoria, no obstante, Rodríguez sienta una postura crítica en cuanto a la efectividad de las comisiones de la verdad y la amnistía.

La experiencia de Centroamérica en proyección a la experiencia colombiana, enseña que para lograr el equilibrio de las dimensiones económicas, políticas, sociales (Restrepo-Yepes, y otros, 2017), de justicia, de tratamiento a las víctimas -y por qué no decirlo-, religiosas (que también inciden en los acercamientos y en las coyunturas de intereses estatales en contraposición), las negociaciones tuvieron que abarcar todos los escenarios de disputa desde el 
más alto nivel hasta el de menor entidad, si se quería evitar el resurgimiento de las hostilidades, que precisamente son extremos a los que se llegan cuando las inconformidades individuales y sociales trascienden de lo sectorial a lo regional o a lo nacional.

\subsection{En Europa}

Kai Ambos (2009) plantea que de acuerdo con la experiencia de justicia de transición en países de Europa como Alemania ${ }^{3}$, Italia ${ }^{4}$ España ${ }^{5}$ dicho concepto demanda una visión más elaborada y que parte de dos ideas centrales. La primera, que el interés de justicia debe tener como complemento los derechos a la verdad,

3 "[...], en el caso alemán se distinguen dos situaciones: a) la transición del nacionalsocialismo a la democracia, y b) el caso de la antigua República democrática alemana (DDR) y la reunificación alemana" (Modolell González, 2008).

4 "Así, en la transición italiana se pueden distinguir tres etapas. La primera entre 1943 y 1946, caracterizada por la exigencia de justicia y el recurso a la vía penal. En dicho lapso la persecución penal se diferenció según la nacionalidad de los autores: los alemanes fueron enjuiciados por tribunales militares, mientras que los italianos civiles fueron enjuiciados por tribunales comunes y los militares italianos por tribunales militares. Para la represión de los hechos, se recurrió a las normas nacionales preexistentes a los hechos cometidos. La segunda etapa se ubica desde el año 1946 en adelante, y se caracteriza por la no persecución de los crímenes. Durante esta etapa se dicta una amnistía para los italianos (salvo los delitos más graves). Por su parte, los procesos contra los alemanes fueron archivados por decisión de la fiscalía en el año 1960. La tercera etapa comienza en el año 2000, y se caracteriza por la reapertura de los juicios contra los alemanes, sin embargo, no se han perseguido el grueso de los casos (persecución minimalista)" (Modolell González, 2008, p. 85).

5 "Tras la muerte de Franco se inicia en España un proceso de transición a la democracia que culmina con la aprobación de la Constitución de 1978" (Payero López, 2016). Ver también: Ripoll Carulla (2014) y Tamarit Sumalla (2014). justicia y reparación de las víctimas de los crímenes internacionales nucleares. La segunda, que se deben desarrollar y aplicar alternativas a la persecución penal, en especial desde la actuación de comisiones de la verdad, sin que dichas medidas alternativas sustituyan la justicia penal.

\begin{abstract}
Ahora bien, se plantea que los orígenes de la justicia transicional moderna se encuentran en la Primera Guerra Mundial, "pero comienza a ser entendida como extraordinaria e internacional en el período de la posguerra después de 1945" (Ambos, 2009, p. 24). Al respecto se describe que, en el período comprendido entre la primera y la segunda guerra mundial, el objetivo central de la justicia era delinear la guerra injusta y delimitar los criterios de un castigo justificable impuesto por la comunidad internacional (Ambos, 2009). De otro lado se expone que, como legado de la posguerra, se incorporaron en el derecho internacional, los precedentes que establecieron los juicios internacionales por los abusos en los tiempos de guerra, entre ellos la Convención contra el Genocidio de 1948 (Ambos, 2009).
\end{abstract}

Se debe tener en cuenta que las experiencias de transición en Europa han sido diferentes, cada una con circunstancias concretas, que implican un análisis desde las dimensiones históricas, sociopolíticas, jurídicas y éticas. Teniendo como común denominador la búsqueda del equilibrio entre los valores de paz y justicia. Se 
reconoce en la experiencia de Europa, que los procesos de justicia transicional no fueron pacíficos y evidenciaron algunas carencias o debilidades, así por ejemplo se observa que "las principales carencias de la justicia de transición en España se refieren a los ámbitos del derecho a la verdad y a la justicia" (Payero, 2016, p. 221).

En el texto La justicia transicional después de la guerra y la dictadura: aprendizajes desde la experiencia europea (Huyse, 2013), un estudio que parte del análisis comparado de las experiencias de transición democrática de Bélgica, Francia, Alemania (Occidental) y Holanda después de la Segunda Guerra Mundial; Grecia, Portugal y España en la década de 1970; y Hungría y Polonia después de 1989, se responde a unas preguntas en común relacionadas con los desafíos de las justicias de transición en estos países, entre ellas: ¿exclusión o inclusión de victimarios?, ¿centrar la atención en victimario o en víctima?, ¿̇olvidar o recordar?, ¿castigar o no?. Al respecto, no se encuentran respuestas uniformes y se describen situaciones disímiles de acuerdo con cada experiencia.

Sin embargo, el estudio también enumera una serie de similitudes en estos procesos de transición, entre ellos: un comienzo caótico (ausencia de un marco claro de coordinación de programas y acciones), toma de decisiones pragmáticas (los países adaptaron parcial o totalmente sus políticas), política centrada en los victimarios (con debilidades en la protección de los derechos de las víctimas dado que el foco central estuvo en los procedimientos de derecho penal), selectividad en las políticas de reparación (principalmente por escasez de recursos), imposición de consideraciones político-estratégicas, procesos de larga duración, y la influencia del mundo exterior.

En definitiva, la justicia de transición ha planteado en todas las sociedades europeas relacionadas, una serie de retos o desafíos comunes, que los ha enfrentado a la inevitable encrucijada: ¿juzgar o perdonar?, ¿excluir o incluir a los victimarios?, ¿priorizar políticas públicas o el respeto del Estado de derecho?, ¿enfoque centrado en las víctimas o en los victimarios?, ¿olvidar o recordar?

En ese sentido, se observa que en el caso colombiano del Acuerdo de Paz suscrito entre el Gobierno Nacional y las Fuerzas Armadas Revolucionarias de Colombia (FARC-EP) tuvo como referencia las experiencias de justicia transicional europeas, lo que permitió definir e incorporar mecanismos judiciales y mecanismos no judiciales de justicia transicional, procurando armonizar: a) el castigo de los delitos más graves con las posibilidades de amnistía y de indulto para los delitos políticos y conexos; b) el castigo de los victimarios con las posibilidades de reinserción social a través de imposición de consecuencias jurídicas no tradicionales; c) la conjugación entre sanciones al victimario y las posibilidades de perdón con memoria histórica. Todos estos aspectos se ven reflejados en el diseño de un Sistema Integral de Verdad, Justicia, Reparación y no Repetición, en el cual se 
Dimaro A. Agudelo M., Liliana D. Pabón G., Luis O. Toro G., Mónica M. Bustamante R. y Orión Vargas V.

circunscribe la denominada Jurisdicción Especial para la Paz y la Comisión de la Verdad, Justicia y Reparación.

Entre los aportes de la experiencia europea en justicia de transición para Colombia, se puede tener en consideración que esta justicia tuvo algunas debilidades en el contexto de continente europeo, las cuales Colombia debe procurar no repetir, las víctimas deben tener derecho a: a) la verdad, entendida como el esclarecimiento de los hechos violatorios de derechos humanos y la delimitación de las responsabilidades correspondientes, b) la justicia, entendida como la protección judicial a sus derechos mediante el acceso al sistema jurídico del Estado, c) la reparación, que comprende la restitución plena, la compensación, la rehabilitación, la satisfacción y la garantía de no repetición.

Finalmente, y con miras a los aprendizajes de los procesos de justicia transicional que se siguieron en Europa, se debe tener en consideración que el diseño y la implementación de mecanismos de justicia transicional debe tener en cuenta la complejidad de los valores y principios que comprende, así como "garantizar una visión holística de justicia, para evitar simplificaciones que afecten a la consecución de una transición realmente justa" (Bonet y Alija, 2009, p. 126).

\subsection{En África}

El conflicto africano, en el contexto del imaginario colectivo de un país rezagado y en guerra como África, tiene su origen en las diferencias étnicas y/o religiosas que imposibilitan su desarrollo como continente y por ende, su capacidad de construir estados verdaderamente funcionales. No obstante, desde una visión más realista, el conflicto armado en África obedece a una lucha por la defensa del poder y de los recursos (Delgado, 2009).

Son diversos los actores nacionales e internacionales que jugaron un papel crucial en la implementación de la justicia transicional en África subsahariana. Estos actores fueron el soporte de las iniciativas de justicia transicional en el marco de muchos esfuerzos realizados para la reconstrucción del posconflicto (Brems, Corradi y Schotsmans, 2015). Esta no es una cuestión en la que los actores nacionales e internacionales tengan un comportamiento "neutral", por el contrario, el impacto político que tienen - de forma directa o indirecta- en las diversas relaciones legales y la forma en que las condiciones bajo las cuales las personas pueden hacer uso de sus derechos fundamentales deja por fuera del contexto cualquier marco jurídico y normativo (Wojkoska y Cunningham, 2010).

Estos actores enfrentan la tarea de vérselas con el hecho de que "la Ley" en África es algo totalmente diferente a "la Ley" en otras latitudes de occidente. El ordenamiento jurídico africano está compuesto por una combinación legal formalizada de: 1) trasplantes legales 
del poder de las antiguas colonias; 2) estructuras cooptadas y transformadas de autoridades con funciones judiciales; $y$ 3) un multivariado rango de mecanismos de resolución alternativa de conflictos, cuya legitimidad deriva de procesos locales, sociales e históricos (Obarrio, 2011, p. 23). De aquí se colige que, ante tal diversidad del ordenamiento jurídico africano, la intervención de los diversos actores en los procesos de justicia transicional no resulta pacifica en forma alguna, máxime cuando la intervención de estos actores (como lo es en el caso de los actores internacionales) tiene un fuerte componente de ayuda financiera para tal propósito (Brems, Corradi y Schotsmans, 2015).

Para los actores internacionales, es de vital importancia que estos procesos giren exclusivamente en torno a las instituciones formales de la justicia y de los procesos legales, en los cuales lo legal y lo técnico, aunado a una visión internacional del derecho y de los derechos humanos, sean la base que fundamenta su acción y por ende, que presenta discordancias (Corradi y Schotsmans, 2015) con el ordenamiento jurídico africano que tiene fuertes raíces en la justica tradicional (Isser, 2011). Para los actores internacionales, la justicia tradicional del ordenamiento jurídico africano llevaría a la implementación de una "justicia pobre" para "personas pobres" y se hacía necesario que quienes al interior del país hicieran parte del posconflicto, se "ajustaran" a los estándares convencionales diseñados en los países modernos (también en posconflicto) (Allen, 2006).
La visión de los actores internacionales en el caso del posconflicto con respecto a los llamados "países frágiles" es una visión de gran riesgo en el surgimiento de nuevos conflictos, lo cual hace necesario que la construcción de la paz esté centrada en la construcción de un nuevo Estado en el cual se refuercen las estructuras y las instituciones (OECD, 2010). De lo anterior se colige que desde esta visión no hay lugar para la justicia tradicional en África. No obstante lo anterior, los actores internacionales han comprendido que el esquema de la justicia transicional en África requiere una pluralidad de actores nacionales e internacionales que provean seguridad y justicia (Albrecht y Buur, 2009).

La justicia tradicional en África es percibida como una dualidad en la que, de un lado se encuentra el hecho de que la intervención de los actores sea efectiva y, del otro, que tal intervención está sometida a múltiples desafíos relacionados con políticas internacionales, derechos humanos y aspectos políticos de orden nacional e internacional que deben ser considerados (Brems, Corradi y Schotsmans, 2015).

Desde esta experiencia, la estrategia a seguir fue identificar la combinación adecuada de mecanismos complementarios que consideraran el contexto específico del posconflicto en el respectivo país, en abierta contraposición a las imposiciones de los actores internacionales, para quienes la visión de la justicia tradicional no tenía cabida alguna en los años 
Dimaro A. Agudelo M., Liliana D. Pabón G., Luis O. Toro G., Mónica M. Bustamante R. y Orión Vargas V.

noventa. Esta estrategia también tenía como fundamento el hecho de que se presentaron otras transiciones luego de los conflictos internos que involucraron una considerable cantidad de ciudadanos (víctimas, victimarios o ambos) (Shaw y Waldorf, 2010).

En este continente se aceptó que la efectividad de este proceso exige una justicia transicional: 1) localizada (Lutz, 2006) (el contexto y la cultura apropiadas); 2) basada en el lugar (Shaw y Waldorf, 2010); y 3) que venga de abajo (McEvoy y McGregor, 2008). Lo anterior exigió una agenda que incluyó el desarrollo y la construcción de una paz duradera acorde con lo señalado en La Agenda Accra del 2008, la Declaración de París de 2005 y las Guías del Comité para el Desarrollo de la OECD (2001). Todo ello se integró en varios documentos internacionales sobre justicia transicional de la Peacebuilding Commission (2009). Frente a esto las Naciones Unidas reconocieron el valor de los mecanismos de justicia transicional basados en la tradición de los pueblos en el escenario del posconflicto (United Nations, 2010):

Para las Naciones Unidas, la justicia es un ideal de responsabilidad e imparcialidad en la protección y reivindicación de los derechos y en la prevención y enjuiciamiento de los errores. La justicia implica el respeto de los derechos del victimario (acusado), el respeto por el interés de las víctimas y por el bienestar de la sociedad en general. Es un concepto arrai- gado en las culturas y tradiciones nacionales $\mathrm{y}$, dado que su administración normalmente emplea mecanismos formalmente establecidos en la Ley, los mecanismos tradicionales de resolución de conflictos son igualmente relevantes.

De acuerdo con lo enunciado, la justicia transicional en África pasa necesariamente por la justicia tradicional, sus costumbres, cultura, tradición, lo cual, al parecer, atenta contra los lineamientos de los actores internacionales frente a los derechos humanos, no obstante, se acerca al concepto asumido en este artículo en relación con la justicia transicional, como la adopción de medidas no judiciales.

\subsection{En Asia}

Asia es un continente que actualmente posee numerosos conflictos, muchos de ellos, en especial en el área de Asia Central, iniciaron con la caída del muro de Berlín y la desintegración de la Unión de Repúblicas Socialistas Soviéticas (URSS), aquí se incluye a los países Uzbekistán, Kazajistán, Tayikistán y Kirguizistán. Si bien algunos conflictos ya existían con anterioridad, la caída del muro de Berlín hizo que se incrementaran las disputas al interior de los países por el control político y económico, en lo que se denomina un conflicto de tipo vertical y que llevó al poder a dirigentes de los partidos comunistas locales, con una denotada concentración de poder y represión en contra de la población, la cual aún persis te y aleja la opción democrática en estos países, y ha llevado al surgimiento de 
movimientos fundamentalistas islámicos (Lascuraín, 2017).

Esta zona, denominada por Mackinder (2004) como hearthland, o región cardinal por su posición geoestratégica de relevancia para Europa y Asia, denominado por otros como Eurasia, es también escenario de múltiples conflictos entre grandes potencias como China, Rusia y Estados Unidos, que ven en esta región opciones de abastecimiento de recursos naturales, especialmente gas y petróleo, sin atención a las necesidades de la población que sufre por una distribución inequitativa de recursos energéticos e hídricos (Campins y Mañé, 2012).

De otro lado, en otras zonas del continente asiático los conflictos son mayoritariamente de tipo horizontal, esto es, de enfrentamiento entre miembros de distintos grupos, por diferencias étnicas, religiosas, territoriales y demás, aquí se incluyen los conflictos de países como Afganistán, Camboya, Indonesia y Myanmar.

En Afganistán el conflicto se ha desarrollado a partir de 1978, fecha en la que sufrieron un golpe comunista, una invasión soviética y una insurgencia muyahidín, además de un régimen talibán opresivo. Por otro lado, a partir de 2001 Afganistán sufrió un ataque militar por parte de los Estados Unidos en la denominada Guerra contra el terrorismo, el cual se dilató hasta el 2011. Actualmente, afronta una delicada situación de conflicto entre talibanes y otros grupos insurgentes, aunque presenta avances en procesos de reconstrucción, elecciones y reformas legales (ICTJ, 2018).

Camboya sufrió durante el gobierno de los jemeres rojos, que llegaron al poder en 1975 y gobernaron por cuatro años. Causaron la muerte de cerca de dos millones de personas a través de trabajo forzado, inanición o simple ejecución. Este conflicto terminó en 1998 con la muerte a manos del ejército vietnamita del líder Pol Pot (ICTJ, 2018).

Indonesia estuvo bajo el régimen del "Nuevo Orden" del General Soeharto de 1965 a 1998. Este período estuvo plagado de violencia y represión generalizada, incluidos abusos sistemáticos en Timor del Este, Aceh y Papua. Se le atribuye la muerte de más de quinientas mil personas, acusadas de pertenecer al Partido Comunista de Indonesia. La mayoría de estas ocurrieron entre 1965 y 1966, aunque el partido oficialista gobernó hasta 1998, fecha en la que el presidente Soeharto dejó el poder (Santa Cruz, 1998).

De los países de Asia, Myanmar -también llamado Birmania- es particularmente diferente. Un tercio de la población pertenece a minorías étnicas o tribales desconocidas por el Estado. La vida entre estas comunidades ha estado marcada por continuos enfrentamientos desde 1948, fecha de su independencia de Inglaterra. Entre sus grupos tribales, los rohinyas son una minoría que ha sufrido la mayor marginación por tratarse de una comunidad que no es reconocida por el 
Dimaro A. Agudelo M., Liliana D. Pabón G., Luis O. Toro G., Mónica M. Bustamante R. y Orión Vargas V.

Estado, poseer un dialecto propio y por su religión, que es una versión sufí del islam, esto ha llevado a que los rohinyas no sean reconocidos como ciudadanos y sean objeto de múltiples operaciones militares para expulsarlos del país (Izquierdo, 2016).

Ahora bien, al abordar la forma en la cual se ha logrado avanzar en la solución de los conflictos en el continente asiático, es necesario diferenciar entre la zona del Hearthland - que no ha tenido procesos de paz propiamente dichos - y los países de Asia del Sur, donde se han llevado a cabo procesos de justicia transicional, los que se han desarrollado de la siguiente manera:

En Afganistán se optó por otorgar amnistías generales a todos los involucrados en el conflicto. También se avanzó en la construcción de memoria histórica y en la formación en derechos humanos (ICTJ, 2018).

En Camboya se creó el tribunal para el enjuiciamiento llamado Tribunal para el Genocidio Camboyano, principalmente para enjuiciar a los líderes superiores del Khmer Rouge, por crímenes de lesa humanidad, genocidio y otros (ICTJ, 2018).

En Indonesia, aunque la mayoría de crímenes ocurrieron entre 1965 y 1966, solo medio siglo después, en 2015, se inició un proceso de reconciliación (Santa Cruz, 1998).

En Myanmar se estableció un tribunal de derechos humanos para enjuiciar a los acusados de crímenes de lesa humanidad y genocidio, sin embargo, las condenas contra los acusados fueron declaradas nulas por los tribunales de segunda instancia. Las iniciativas legislativas se orientan a otorgar amnistía general a los involucrados (Izquierdo, 2016).

En el caso de Asia, la justicia transicional es diferente de acuerdo con la ubicación geográfica, por cuanto en la región norte, si bien han existido conflictos, no se han llevado a cabo procesos de paz propiamente dichos, debido a la presión impuesta por regímenes dictatoriales y represiones generalizadas. Situación diferente al sur del continente donde se han creado tribunales de paz y se han concedido amnistías cuestionadas por ir en contravía a los instrumentos internacionales sobre derechos humanos, en especial, por el otorgamiento de autoamnistías por delitos de lesa humanidad.

\section{APORTES DESDE LA EXPERIENCIA DE OTRAS REGIONES A LA JUSTICIA TRANSICIONAL EN COLOMBIA}

Frente a los procesos de justicia transicional a nivel mundial, el Secretario General de las Naciones Unidas, en un informe presentado en el 2004, indicó que las instituciones internacionales deben ayudar a fomentar la capacidad y el funcionamiento de los tribunales nacionales y a la reparación, la búsqueda de la verdad, programas de reparación, la implementación de políticas de justicia transicional y la protección efectiva de los derechos fundamentales (Almqvist y Espósito, 2009), a fin de asegurar el 
principio del Estado de derecho (Almqvist y Espósito, 2009). Para ello, deben indicar cómo resuelven los tribunales los problemas relacionados con leyes de amnistía o aquellas que reduzcan el castigo a quienes cometan crímenes graves, la favorabilidad aplicable a este tipo de casos, el acceso a las pruebas, el procedimiento frente a la prueba, la prueba con relación a crímenes de escala masiva, la forma de investigación, de juzgamiento y sanción de los responsables, la garantía de los derechos de las víctimas a la justicia

Como consecuencia de lo anterior, se han identificado los siguientes aportes por regiones para la justicia transicional en Colombia:

\section{Desde América del Sur}

La justicia transicional en Colombia no debe girar solamente en torno al desarrollo de procesos penales que apunten a la responsabilidad penal de los presuntamente responsables, con aplicación de sanciones judiciales y administrativas por las violaciones; se hace necesario implementar otras medidas como las comisiones de la verdad, a fin de encontrar la verdad frente a los crímenes cometidos, las desapariciones y la tortura. La reparación a la víctima y la reconciliación con la misma son también fundamentales, a fin de evitar resentimientos. Frente a este tema, Paul Van Zyl indicó que la justicia transicional, dentro de sus elementos claves, requiere "enjuiciar a los perpetradores, revelar la verdad acerca de crímenes pasados, brin- dar reparaciones a las víctimas, reformar las instituciones abusivas y promover la reconciliación" (2011, p. 49). Lo que conduce a afirmar que en Colombia se debe implementar una justicia basada en la reconciliación, que busque cumplir principalmente con cuatro mecanismos: "enjuiciamientos penales, reparaciones, reforma institucional y búsqueda de la verdad" (Seils, 2009, p. 23).

Lo anterior permite inferir que al interior del Estado se deben establecer políticas que fortalezcan las obligaciones legales internacionales y el consenso normativo, la creación de comisiones de verdad fuertes y la puesta en funcionamiento de programas oficiales de reparaciones a las víctimas; la existencia de museos de memoria en homenaje a las mismas, velar por la coordinación y cooperación entre tribunales de tal forma que se creen mecanismos de colaboración efectiva, incluso transfronteriza, el funcionamiento del modelo penal de forma acusatoria con celeridad de plazos; la concesión de amnistías e indultos - pero analizados conforme a la realidad social a fin de no generar descontento en la sociedad-, el establecimiento de programas eficaces de protección de testigos y la creación de una base de datos en la cual se registren los testimonios de cada una de las víctimas, que permita el cruce de información. Es decir que se requiere una estrategia integral del Estado en pos de la justicia retributiva, que "adelante los procesos en un tiempo útil que resguarde los derechos de los acusados, de las víctimas y de la sociedad" (Gil, 2009, p. 67). 
Dimaro A. Agudelo M., Liliana D. Pabón G., Luis O. Toro G., Mónica M. Bustamante R. y Orión Vargas V.

Solo atendiendo a lo anterior se puede lograr una justicia constitutiva, que logre una confianza entre los ciudadanos y las instituciones; porque como lo indica Ezequiel Malarino en su capítulo "Breves reflexiones sobre la justicia de transición a partir de las experiencias latinoamericanas", los principales aportes de la experiencia latinoamericana para la justicia transicional, son:

\section{[...] la verdad como reparación a las víctimas y como base para la reconciliación y la consolidación de la nueva sociedad. Por el otro, en lo que atañe al rol del derecho penal como herramienta de superación del pasado, esto es, a la cuestión de la tensión, siempre presente en los procesos de transición, entre justicia y paz, que se refleja en la contraposición entre el reclamo por la persecución penal de los críme- nes y la necesidad en ciertos casos de conceder amnistía. (2009, p. 415)}

Indica de esta forma que en ocasiones es mejor renunciar al derecho penal en pos de la paz como interés superior, pues este es el pilar fundamental de una justicia de transición; solo con ello se logrará la reconciliación social, la consolidación de vínculos entre sectores del conflicto, el cierre de heridas sociales, la reanudación de las relaciones sociales y la consolidación de las instituciones democráticas en un Estado social de derecho (Malarino, 2009).

\section{Desde Centroamérica}

La experiencia de los países que integran esta región deja como contribución a Co- lombia lo siguiente: para lograr acercamientos de paz, es fundamental debilitar la capacidad de confrontación guerrillera y con ello, desestimular la pretensión de tomarse el poder por la vía armada de forma sostenida en todo el territorio nacional; igualmente, se evidencia la importancia de la profesionalización de la fuerza pública y el mejoramiento de su proximidad a la comunidad, la necesidad de pactar tratamientos especiales para los grupos insurgentes a través de leyes de amnistía e indulto compatibles con la jurisdicción internacional sobre Derechos Humanos como estrategia ineludible para facilitar el retorno de este segmento de población a la legalidad; complementario a ello, está el permitir su participación en política en igualdad formal y de trato, pero sobre todo, es ineludible el compromiso de todos los actores en la búsqueda de la verdad, siendo importante para ello la consolidación de esfuerzos a través de comisiones especiales de la verdad como eje para la reparación efectiva de las víctimas.

En el orden de gobernabilidad y confianza ciudadana, las políticas públicas del posconflicto deben ser integrales y con orientación a respetar la independencia de los poderes del Estado y la libertad de escoger los programas de gobierno amigables con la necesidad social y las víctimas de la violencia, más allá de las imposiciones de ideas, credos políticos por la vía armada o a través de la oposición partidista de forma desmesurada, lo que incluye reformas económicas de equidad previstas, en relación con las situaciones reales de los ciudadanos y 
la justicia en la repartición de los bienes y servicios públicos, con focalización en todas las clases sociales para limitar, en gran medida, los monopolios económicos y sociales, que de alguna manera habrían incentivado las disputas y con ello, el origen de los conflictos estudiados.

En cuanto a los retos de la justicia transicional, la región centroamericana, en un ámbito de conocimiento que no solo se delimita por su pasado, sino también por su presente, muestra que la implementación de los acuerdos de paz debe ser llevados a la realidad material de forma constante, más allá de los formalismos, extendiendo su impacto a todos los órdenes de criminalidad, problemas de convivencia y entornos de seguridad social integral.

\section{Desde Europa}

Al tener en cuenta la experiencia de los países europeos que transitaron por este tipo de justicia, se hace necesario revisar los siguientes escenarios: la necesidad de articulación de todos los poderes públicos para la superación de las diferencias y la armonización de las instituciones; la definición clara de políticas públicas coherentes con el contenido del Acuerdo de $\mathrm{Paz}$, que se constitucionalicen y cuenten con la protección de los derechos humanos; un desarrollo legislativo coherente con la protección de los derechos de las víctimas; la disposición de los recursos públicos suficientes para la ejecución de las políticas públicas, la implementación de la normativa, en especial para la reparación de la víctimas; y finalmente, como presupuesto esencial, la implementación de la Jurisdicción Especial para la Paz en armonía con los estándares internacionales, esto es, que actúe en coherencia con lo que trazan los tratados, convenios y convenciones sobre derechos humanos suscritos por Colombia para el necesario respeto de los derechos de las víctimas a la verdad, justicia y reparación y el respeto a los juzgados del debido proceso.

\section{Desde África}

Este continente, con sus conflictos y la voluntad sectorial de reconstruir el tejido jurídico y social en ámbitos de justicia transicional, deja como experiencias para Colombia: la unidad política debe ser un patrimonio indeclinable; la democracia debe ser sostenida y oportunamente, se debe hacer frente a las dictaduras o los monopolios sociales que la comprometan; la justicia debe ser asumida por el Estado desde prácticas acordes a los derechos de las personas; los gobiernos deben ser de unidad nacional y estar orientados a políticas de cumplimiento de los acuerdos de paz, sin importar la línea de pensamiento, orientación, pensamiento político o religioso; lo acordado no puede comprometer la seguridad jurídica y la estabilidad social en el orden nacional e internacional, por ello todos los procesos dirigidos a tratamientos alternativos de justicia deben contar con el acompañamiento y asesoría de la comunidad internacional.

\section{Desde Asia}

La mayoría de los conflictos existentes en Asia han tenido un trasfondo ideológico, 
principalmente entre ideologías de corte capitalista y otras de corte marxista o comunista. Parte de la solución alcanzada en los diferentes países asiáticos ha estado basada en reconocer equilibrios entre ambas ideologías y evitar extremos absolutos. En cuanto a amnistías generales en la experiencia asiática, se debe asumir que esta forma de amnistía no es conveniente en la situación actual colombiana, no solo por el compromiso de debida judicialización interna -en cuanto a los sujetos comprometidos- sino también por las caracterizaciones de los delitos, dado su impacto nacional o internacional. De otro lado, en cuanto a los tribunales de paz, el Estado colombiano puede aprender de la experiencia asiática en el sentido de poner en funcionamiento y confiar en estos en tanto jurisdicción natural para posibilitar la recuperación de la memoria histórica, efectivizar la administración de justicia especial y garantizar -desde el punto de vista formal y material- los derechos de las víctimas. Finalmente, la política de silencio que ha operado en algunos Estados de Asia no favorece la intencionalidad colombiana de conocer toda la verdad sobre lo acontecido y tomar medidas eficaces para confinar el daño y garantizar un mejor futuro.

Todo lo expuesto demuestra que, si bien cada experiencia de justicia transicional ha tenido un origen y un desarrollo diferente, se identifica como principal aporte que un proceso de justicia transicional debe tener como parámetro de orientación los estándares internacionales sobre el respeto de los Derechos Humanos y el reconocimiento de los derechos de las víctimas. Y es este precisamente el principal aprendizaje para Colombia a fin de no repetir los errores del pasado y alcanzar la consolidación de una paz estable y duradera.

\section{CONCLUSIONES}

- En el caso de América del Sur, son diversos los conflictos que se presentaron fruto de conflictos armados o de regímenes dictatoriales, en algunos el cambio de régimen no llevó a que se asumieran de forma inmediata procesos de justicia transicional y se adoptaran mecanismos para ello, por cuanto incluso existen aún crímenes en la impunidad. No obstante, en otros Estados se implementó o se han venido implementando medidas judiciales y no judiciales para lograr una justicia retributiva (en la que los responsables paguen ante el Estado), o una justicia restaurativa (en la que respondan ante la misma sociedad), siempre en pos de generar una fuerte tensión entre justicia y verdad. Este es uno de los mayores aportes para Colombia: la búsqueda de armonizar la justicia restaurativa y la retributiva.

- Las experiencias vividas en Centroamérica deben ser precedentes obligatorios para el Gobierno, el Congreso de la Republica y la JEP (Jurisdicción Especial para la Paz) en Colombia, a fin de ser persistentes en la voluntad, diseño y ejecución de políticas y acciones para cumplir 
con lo acordado en sus diferentes temáticas, en función de las víctimas, los actores del conflicto y la sociedad nacional.

- En la experiencia de justicia transicional en Europa: a) Alemania con la transición del nacionalismo a la democracia y con la reunificación alemana; b) Italia con la apertura de juicios contra alemanes por graves violaciones de derechos humanos; c) España con su proceso de transición tras la muerte de Franco para la recuperación de la democracia; d) Bélgica, Francia y Holanda con sus transiciones después de la Segunda Guerra Mundial; e) Grecia y Portugal con los procesos de transición en la década de 1970, han sido referentes para Colombia en el diseño e implementación de mecanismos judiciales y no judiciales de justicia transicional que procuran armonizar el castigo de los delitos más graves con las posibilidades de amnistía y de indulto para los delitos políticos y conexos; el castigo de los victimarios con las posibilidades de reinserción social a través de imposición de consecuencias jurídicas no tradicionales; y la conjugación entre sanciones al victimario y las posibilidades de perdón con memoria histórica.

- La experiencia de justicia transicional en África ilustra la importancia del respeto de la justicia tradicional, esto es, las costumbres y tradiciones en procura de la armonía social.
- De la experiencia de Asia es importante reconocer equilibrios entre ideologías capitalistas y marxistas y evitar extremos absolutos para acercar a las partes y crear espacios de diálogos; la creación de tribunales de paz ha facilitado el acceso a la verdad y a la creación de memoria histórica, a la vez que se condena el silencio y las autoamnistías por favorecer la revictimización y generar espacios para revivir la violencia.

- La justicia transicional, como tema de estudio desde la visión comparada, es de gran relevancia por los tiempos de esperanza social e institucional por los que pasa el Estado colombiano, las experiencias de otras naciones ubicadas en América Central, América del Sur, Europa, África y Asia, permiten contextualizar la realidad antecedente y actual, y lo que se requiere a posteriori mediante políticas públicas, compromisos de los actores del conflicto y la sociedad para lograr, entre otros factores, la recuperación de la tranquilidad, la economía, la legitimidad y la confianza institucional.

- Es evidente, desde estas experiencias, que los aportes a la justicia transicional están fincados en la reparación integral de las víctimas y la judicialización y sanción penal de los agentes perpetradores de crímenes relacionados con el conflicto o ejecuciones delictuales relacionadas en las formas dictatoriales de gobierno. 
Dimaro A. Agudelo M., Liliana D. Pabón G., Luis O. Toro G., Mónica M. Bustamante R. y Orión Vargas V.

\section{REFERENCIAS}

Aguirre, K. (2014). Analizando la violencia del conflicto: El caso en Guatemala un estudio sub-nacional. Revista Mexicana de Ciencias Políticas y Sociales, (220), 191-234.

Albrecht, P., y Buur, L. (2009). Trial Justice. The International Criminal Court and the Lord's Resistance Army. London/New York: Zed Books.

Allen, T. (2006). Trial Justice. The International Criminal Court and the Lord's Resistance Army. London/New York: Zed Books.

Alfonso, C. (2009). Informe Nacional - Paraguay. En K. Ambos, E. Malarino y G. Elsner (Eds.), Justicia de Transición. Informes de América Latina, Alemania, Italia y España (pp. 345-355). Uruguay: Konrad Adenauer Stiftung. Recuperado de https://www.kas.de/c/document_library/ get_file?uuid=c6012f10-4557-5aa7-12dc-ca c8ef7c350f\&groupId $=252038$

Almqvist, J., y Espósito, C. (Coords.) (2009). Justicia transicional en Iberoamérica. Cuadernos y debates. Madrid: Centro de estudios políticos y constitucionales.

Ambos, K. (2009). El marco jurídico de la Justicia de Transición. En K. Ambos, E. Malarino y G. Elsner (Eds.), Justicia de Transición. Informes de América Latina, Alemania, Italia y España (pp. 23 -129). Uruguay: Konrad Adenauer Stiftung. Recuperado de https://www.kas. de/c/document_library/get_file?uuid $=\mathrm{c} 6$ 012f10-4557-5aa7-12dc-cac8ef7c350fEgrou $\underline{\mathrm{pId}=252038}$

Ambos K., Malarino E. y Elsner, G. (2009). Justicia de transición. Informe de América Latina, Alemania, Italia y España. Uruguay: Konrad Adenauer Stiftung. Recuperado de https://www.kas. de/c/document_library/get_file?uuid $=\mathrm{c} 6$ 012f10-4557-5aa7-12dc-cac8ef7c350fEgrou $\underline{\mathrm{pld}=252038}$
Brems, E., Corradi, G., y Schotsmans, M. (2015). International Actors and Traditional Justice in Sub-Saharan Africa. Policies and Interventions in Transitional Justice and Justice Sector Aid. Cambridge: Intersentia Ltd.

Bonet Pérez, J., y Alija Fernández, R. A. (2009). Impunidad, derechos humanos y Justicia transicional. Cuadernos Deusto de Derechos Humanos. Número 53. Bilbao: Universidad de Deusto. Instituto de Derechos Humanos. Recuperado de http://www.deusto-publicaciones.es/ deusto/pdfs/cuadernosdcho/cuadernosd cho53.pdf

Bustamante Rúa, M.M. Pabón Giraldo, L.D., y Toro Garzón, L.O (2017). La justicia de transición en Colombia: breve estudio de la dimensión procesal. Medellín: Sello editorial Universidad de Medellín.

Campins Eritja, M., y Mañé Estrada, A. (Coords. y Eds.) (2014). Building a Regional Framework in Central Asia: Between Cooperation and Conflict. Barcelona: Institut Català Internacional per la Pau. Recuperado de http://icip.gencat. cat/web/.content/continguts/publicacions/ arxius_icip_research/WEB_Llibre-ICIP . Research_2014.pdf

Caro Coria, D.C. (2009). Informe Nacional - Perú. En K. Ambos, E. Malarino y G. Elsner (Eds.), Justicia de Transición. Informes de América Latina, Alemania, Italia y España (pp. 357-390). Uruguay: Konrad Adenauer Stiftung. Recuperado de https://www.kas.de/c/document_library/ get file?uuid=c6012f10-4557-5aa7-12dc-ca c8ef7c350fEgroupId $=252038$

Corradi, G., y Schotsmans, M. (2015). International actors and traditional justice in Africa. En Eva Brems, G. Corradi, y M. Schotsmans. (Eds.), International actors and traditional justice in sub-Saharan Africa (pp. 3-15). Cambridge-Antwerp-Portland: Intersentia.

Corte Constitucional de Colombia. Sentencia C 579 de 2014. MP Jorge Ignacio Pretelt Chaljub. 
Chernick, M. (1998). Las dimensiones internacionales de los conflictos internos en América Latina: de la Guerra Fría (a la paz negociada en Centroamérica) a la Guerra Antinarcótica. Revista Colombia Internacional (41), 5-43. Recuperado de https://revistas.uniandes.edu.co/ doi/pdf/10.7440/colombiaint41.1998.01

Delgado Caicedo, J. (2009). Paz y seguridad humana en África: una visión desde la Unión Africana. Oasis, (14), 159- 167.

Díaz Barrado, C. M., Romero Serrano, J., y Moran Blanco, S. (2010). Los conflictos armados de Centroamérica. Conflictos internacionales contemporáneos 13. Madrid: Ministerio de Defensa.

Elster, J. (2006). Rendición de cuentas la justicia transicional en perspectiva histórica. Buenos Aires: Katz editores.

Galain Palermo, P. (2009). Informe Nacional Uruguay. En K. Ambos, E. Malarino y G. Elsner (Eds.), Justicia de Transición. Informes de América Latina, Alemania, Italia y España (pp. 391 -414). Uruguay: Konrad Adenauer Stiftung. Recuperado de https://www.kas. $\mathrm{de} / \mathrm{c} /$ document_library/get file?uuid $=\mathrm{c} 6$ 012f10-4557-5aa7-12dc-cac8ef7c350fEgrou $\mathrm{pId}=252038$

Garretón, R. (2009). Los tribunales con jurisdicción penal durante la transición a la democracia en Chile. En J. Almqvist y C. Espósito (Coords.), Justicia transicional en Iberoamérica (pp. 69-85). Madrid: Centro de Estudios Políticos y Constitucionales.

Gil Lavedra, R. (2009). Justicia transicional en Argentina: el papel de los tribunales penales. En J. Almqvist y C. Espósito (Coords.), Justicia transicional en Iberoamérica (pp. 43-67). Madrid: Centro de Estudios Políticos y Constitucionales.

Guzmán Dalbora, J. L. (2009). Informe nacional - Chile. En K. Ambos, E. Malarino y G. Elsner (Eds.), Justicia de Transición. Informes de América Latina, Alemania, Italia y España (pp. 201 -234). Uruguay: Konrad Adenauer Stiftung. Recuperado de https://www.kas. de/c/document_library/get_file?uuid =c6 012f10-4557-5aa7-12dc-cac8ef7c350fEgrou $\mathrm{pId}=252038$

Huyse, L. (2013). Transitional justice after war and dictatorship, Learning from european experiences (1945-2000). Bruselas: Centre for Historical Research and Documentation on War and Contemporary Society CEGES-SOMA. Recuperado de http:// www.cegesoma.be/docs/media/Recherche/ TransJustFinalReport.pdf

Izquierdo, J. (2016). La exclusión de los rohinyás de Birmania: un viejo desafío para un nuevo gobierno [Documento de análisis n. ${ }^{\circ}$ 26]. Instituto Español de Estudios Estratégicos. Recuperado de http://www.ieee.es/Galerias/fichero/ docs_analisis/2016/DIEEEA26-2016_Rohinyas_Birmania_MJIA.pdf

International Center for Transitional Justice (ICT)) (2009). Justicia transicional en América Latina: Enfrentando los dilemas del presente a partir de los legados del pasado. Recuperado de https://www. ictj.org/sites/default/files/ICTJ-Global-TransitionalJustice-in-Latin-America-2009-Spanish.pdf

Isser, D. (Ed.) (2011). Customary Justice and the Rule of Law in War-Torn Societies. Washington D.C: United States Institute of Peace Press.

Lascuraín, M. (2017, abril-junio). El papel geoestratégico de Asia Central. Foro Internacional 228, 57(2), 389-421. Recuperado de http:// www.scielo.org.mx/pdf/fi/v57n2/0185-013Xfi-57-02-00389.pdf

Lutz, E. (2006). Transitional Justice. Lessons learned ant the road ahead. En N. Roht Arriaza y J. Mariezcurrena, Transitional Justice on the Twenty-First Century. Beyondtruth versus justice (pp. 325-341). Cambridge: Cambridge University Press.

Malarino, E. (2009). Breves reflexiones sobre la justicia de transición a partir de las 
Dimaro A. Agudelo M., Liliana D. Pabón G., Luis O. Toro G., Mónica M. Bustamante R. y Orión Vargas V.

experiencias latinoamericanas. En K. Ambos, E. Malarino y G. Elsner (Eds.), Justicia de Transición. Informes de América Latina, Alemania, Italia y España (pp. 415-431). Uruguay: Konrad Adenauer Stiftung. Recuperado de https:// www.kas.de/c/document_library/get_file? uuid $=$ c6012f10-4557-5aa7 -12 dc - cac8ef7c3 50fEgroupld $=252038$

McEvoy, K. y McGregor, L. (eds.) (2008). Transitional Justice from Below. Grassroots Activism and the Struggle for Change. Oxford/Portland, OR: Hart Publishing

Mackinder, H. J. (2004). The Geographical Pivot of History (1904). The Geographical Journal, 170(4), 298-321.

Matul, D. y Ramírez, A. (2009). El proceso de paz en Centroamérica. Agendas pendientes y nuevos focos de conflictividad. Los casos de Guatemala y Nicaragua. Revista Pensamiento Propio, 14(29), 91 -117. Recuperado de http:// www.gloobal.net/iepala/gloobal/fichas/ficha. php?id=9581Eentidad $=$ Textos\&html $=1$

Martínez Ventura, J. (2009). Informe nacional - El Salvador. En K. Ambos, E. Malarino y G. Elsner (Eds.), Justicia de Transición. Informes de América Latina, Alemania, Italia y España (pp. 301-323). Uruguay: Konrad Adenauer Stiftung. Recuperado de https://www.kas. $\mathrm{de} / \mathrm{c} /$ document_library/get_file?uuid $=\mathrm{c} 6$ 012f10-4557-5aa7-12dc-cac8ef7c350fEgrou $\mathrm{pld}=252038$

Modolell González, J. L. (2008, abril 1-4). La Justicia de transición en América Latina y Europa, y la jurisprudencia de la Corte Penal Internacional. Informe del VI Seminario del Grupo Latinoamericano de Estudio sobre Derecho Penal Internacional (Valparaíso, 1 a 4 de abril). Zeitschrift für Internationale Strafrechtsdogmatik, 82-87. Recuperado de https://www.kas.de/c/document_library/ get _file?uuid=bb494dif-5be9-3d3d-aebfc08dee8b9708\&groupId $=252038$
Obarrio, J. (2011). Transitional Justice as rule of law in Africa: and anthropological perspective. En C. Lekha-Sriram, O. Martín-Ortega y J. Herman (Eds.), Peace Building and the Rule of Law in Africa. Just Peace? (pp. 21-43). London/ New York: Routledge.

OECD (2001). Helping Prevent Violent Conflict: Part I: Helping Prevent Violent Conflict: Orientations for External Partners - Part II: Conflict, Peace and Development Co-operation on the Threshold of the 21st Century, The DAC Guidelines. París: OECD Publishing. https://doi. org/10.1787/9789264194786-en

OECD (2001). The DAC guidelines. OECDiLibrary. Recuperado de https://www.oecd-ilibrary.org/development/the-dac-guidelines_19900864

OECD (2010). The State's Legitimacy in Fragile Situations: Unpacking Complexity, Conflict and Fragility. París: OECD Publishing. https://doi. org/10.1787/9789264083882-en

Pabón Giraldo, L. D., Bustamante Rúa, M. M. y Toro Garzón, L. O. (2017). La legitimidad de la justicia transicional en Colombia: una mirada procesal desde del derecho internacional. En C. Agudelo Mejía, L. D. Pabón Giraldo, L. O. Toro Garzón, M. M. Bustamante Rúa y O. Vargas Vélez (Coords.), Justicia transicional (pp. 149-182). Medelín: Sello editorial Universidad de Medellín.

Payero López, L. (2016). Justicia de transición en España: claves para aprobar una asignatura pendiente. Revista de Paz y Conflictos, 9(1), 209-234. Recuperado de https://dialnet. unirioja.es/descarga/articulo/5569867.pdf

Parenti, P.F. y Pellegrini, L. (2009). Informe Nacional - Argentina. En K. Ambos, E. Malarino y G. Elsner (Eds.), Justicia de Transición. Informes de América Latina, Alemania, Italia y España (pp. 133-152). Uruguay: Konrad Adenauer Stiftung. Recuperado de https://www.kas. de/c/document_library/get_file?uuid=c6 
012f10-4557-5aa7-12dc-cac8ef7c350fEgrou $\mathrm{pId}=252038$

Peacebuilding Commission, y Working Group on Lessons Learned. (2009). Lessons Learned from National Dialogue in Post Conflict Situations. United Nations. Recuperado de https://www.un.org/peacebuilding/sites/ www.un.org.peacebuilding/files/documents/ wgll_14_oct_chair_summary.pdf

Restrepo-Yepes, O. C., Restrepo-Ruiz, A., Molina-Betancur, C. M., Molina-Saldarriaga, C. A., Giraldo-Ramirez, D. P., Carrasquilla-Salazar, D. A., ... Moreno Mosquera, V. J. (2017). Seguridad alimentaria y derecho a la alimentación en escenarios de posconflicto. Análisis, para determinar estándares de política pública, del acuerdo "Política de desarrollo agrario integral", logrado entre Gobierno nacional de Colombia y las FARC - EP . Medellín: Sello Editorial Universidad de Medellín, Sello Editorial Universidad Pontificia Bolivariana, Sello Editorial Instituto Universitario de Enviago y Sello Editorial Unisabaneta.

Ripol Carulla, S. (2014, julio-diciembre). La Justicia de Transición: Concepto y práctica española (selección de bibliografía y documentación). Historiografías, 8, 76-107. Recuperado de http://www.unizar.es/historiografias/numeros/8/ripol_res.pdf

Rocha de Assis, M. T., Coelho Zili, M. A., y Monteconrado Ghidalevich, F. G. (2009). Informe Nacional - Brasil. En K. Ambos, E. Malarino y G. Elsner (Eds.), Justicia de Transición. Informes de América Latina, Alemania, Italia y España (pp. 171-191). Uruguay: Konrad Adenauer Stiftung. Recuperado de https://www.kas. de/c/document_library/get_file?uuid $=\mathrm{c} 6$ 012f10-4557-5aa7-12dc-cac8ef7c350fEgrou $\mathrm{pId}=252038$

Rodríguez Montenegro, G. (2011). Los límites al perdón. Notas sobre la justicia transicional en Sudáfrica, Centroamérica y Colombia. Justicia Juris, 7(2), p..52-66. Recuperado de https://dialnet.unirioja.es/descarga/articulo/4122138.pdf

Santa Cruz, A. (1998, abril-junio). Indonesia, cel precio del autoritarismo). Revista México y la Cuenca del Pacífico, 1(2). Recuperado de http:// www.mexicoylacuencadelpacifico.cucsh.udg. mx/index.php/mc/article/view/18/23

Santalla Vargas, E. (2009). Informe Nacional - Bolivia. En K. Ambos, E. Malarino y G. Elsner (Eds.), Justicia de Transición. Informes de América Latina, Alemania, Italia y España (pp. 153-170). Uruguay: Konrad Adenauer Stiftung. Recuperado de https://www.kas. de/c/document_library/get_file?uuid $=c 6$ 012f10-4557-5aa7-12dc-cac8ef7c350fEgrou $\mathrm{pId}=252038$

Seils, P. (2009). La restauración de la confianza cívica mediante la justicia transicional. En J. Almqvist y C. Espósito (Coords.), Justicia transicional en Iberoamérica (pp. 21-40). Madrid: Centro de Estudios Políticos y Constitucionales.

Shaw, R. y Waldorf L. (2010). Localizing transitional justice. Interventions and priorities after mass violence. Stanford, CA: Stanford UniversityPress.

Tamarit Sumalla, J. (2014). Memoria histórica y justicia transicional en España: el tiempo como actor de la justicia penal. Anuario Iberoamericano de Derecho Internacional Penal, 2, 43-65. http://dx.doi.org/10.12804/anidip02.01.2014.02

United Nations (2004). The Rule of Law and Transitional Justice in Conflict and Post-Conflict Societies, Report of the Secretary-General, S/2004/616. Recuperado de https://www.un.org/ruleoflaw/ blog/document/the-rule-of-law-and-transitional-justice-in-conflict-and-post-conflict-societies-report-of-the-secretary-general/

United Nations (2010, marzo). Guidance Note of the Secretary-General. United Nations Approach to Transitional Justice. Recuperado de https:// www.un.org/ruleoflaw/files/TJ Guidance_Note_March_2010FINAL.pdf 
Dimaro A. Agudelo M., Liliana D. Pabón G., Luis O. Toro G., Mónica M. Bustamante R. y Orión Vargas V.

Van Zyl, P. (2011). Promoviendo la justicia transicional en sociedades post conflicto. Parte I. Conceptos y debates sobre la justicia transicional. En F. Reátegui. (Ed.), Justicia transicional. Manual para América Latina (pp. 47-72). Brasilia y Nueva York: ICTJ.
Wojkowska, E., y Cunningham, J. (2010). Justice Reform's New Frontier: Engaging with Customary Systems to Legally Empower the Poor. En S. Golub (ed.) Legal Empowerment: Practitioners' Perspective. Rome; International Law and Development Organization. 